\title{
Elemental carbon exposure and lung function in schoolchildren from Mexico City
}

\author{
A. Barraza-Villarreal*, M.C. Escamilla-Nuñez*, L. Hernández-Cadena*, \\ J.L. Texcalac-Sangrador*, J.J. Sienra-Monge ", B.E. del Río-Navarro\#", \\ M. Cortez-Lugo*, P.D. Sly ${ }^{\uparrow,+}$ and I. Romieu*, ${ }^{\star,}$
}

ABSTRACT: Though exposure to air pollution has a detrimental effect on respiratory health, few studies have examined the association between elemental carbon exposure and lung function among schoolchildren. The aim of the present study was to present the association between short-term elemental carbon exposure and lung function in schoolchildren from Mexico City.

55 asthmatic and 40 non-asthmatic children were followed for an average of 22 weeks. A spirometry test was performed every 15 days during follow-up. Portable air samplers collected particulate matter onto Teflon filters. Gravimetric analysis was conducted and elemental carbon was quantified using transmission densitometry. The association between the main variables was analysed using linear mixed effects models.

The mean \pm SD of elemental carbon light absorption was $92.7 \pm 54.7 \mathrm{Mm}^{-1}$. An increase of one interquartile range in the 24-h average of elemental carbon $\left(100.93 \mathrm{Mm}^{-1}\right)$ was associated with a significant negative impact on forced expiratory volume in $1 \mathrm{~s}(\mathrm{FEV} 1)(-62.0(95 \% \mathrm{Cl}-123.3--1.2) \mathrm{mL})$ and forced expiratory flow at $25-75 \%$ of forced vital capacity (FVC) (FEF25-75\%) (-111 (95\% Cl -228.3- -4.1) $\mathrm{mL}$ ) among asthmatic children, equal to $3.3 \%$ and $5.5 \%$, respectively; and on $\mathrm{FEV}_{1}$ (-95.0 (95\% Cl -182.3- -8.5) $\mathrm{mL})$ and FVC (-105.0 (95\% Cl -197.0--13.7) $\mathrm{mL}$ ) among non-asthmatic children.

Exposure to elemental carbon resulted in an important negative effect on lung function in atopic schoolchildren, regardless of asthma status.

KEYWORDS: Air pollution, asthma, elemental carbon, epidemiology, lung function, schoolchildren

$\mathbf{V}$ ehicular traffic is a major source of air pollutants and studies from different parts of the world have documented the relationship between exposure to air pollution and poorer respiratory health among children [1-5]. Children living in southern California who are exposed to traffic-related pollution have been reported to have lower lung function, with negative associations reported between the forced expiratory volume in $1 \mathrm{~s}$ (FEV1) and nitrogen dioxide, acid vapour, elemental carbon (EC) and particles with a mean aerodynamic diameter $<2.5 \mu \mathrm{m}$ (PM2.5) [1]. Furthermore, KULKARNI et al. [6] examined alveolar macrophages in induced sputum from children living in Leicester, UK, and found a negative association between lung function and the amount of carbon seen in macrophages.

Experimental evidence from animals and humans has suggested that diesel exhaust particles may have a greater negative impact on respiratory health than other air pollutants $[7,8]$. The metropolitan Mexico City area is one of the biggest and most polluted urban areas in the world, with close to $85 \%$ of air pollutants coming from motor vehicles. One of the main pollutants consists of fine particles (PM2.5), 20\% of which come from industry, $32 \%$ from diesel and $25 \%$ from gasoline [9]. The toxicity of the particles is a subject of interest for epidemiological research [10], and one of the most likely toxic components of the particles are elemental and organic carbon fractions of PM2.5 originating mostly from incomplete combustion of fossil fuels [10]. The association of ambient PM2.5 concentrations with an increased inflammatory response and decreased lung function in Mexican schoolchildren has been previously reported [11, 12]. The present study was undertaken to expand on our previous studies involving the association between exposure to traffic-related pollution and poorer respiratory health in children. We evaluated the association between exposure to EC (as a marker for diesel exhaust particles) and lower lung function in children. We hypothesised that short-term exposures to traffic-related EC was related to decrements in lung function in this population.

\section{AFFILIATIONS}

*Instituto Nacional de Salud Pública, Cuernavaca,

\#Hospital Infantil de México, Federico Gómez, Mexico City, Mexico,

-Division of Clinical Sciences, Telethon Institute for Child Health Research and Centre for Child Health Research, University of Western Australia, Perth,

${ }^{+}$Queensland Children's Medical Research Institute, University of Queensland, Brisbane, Australia, and ${ }^{\S}$ International Agency for Research on Cancer (IARC), Lyon, France.

CORRESPONDENCE

I. Romieu

Instituto Nacional de Salud Publica

Av. Universidad \# 655

Col. Santa Maria Ahuacatitlán

62100

Cuernavaca

Morelos

Mexico

E-mail: iromieu@correo.insp.mx

Received:

July 142010

Accepted after revision:

Jan 102011

First published online:

Feb 102011 


\section{MATERIAL AND METHODS}

\section{Study design}

The children in the present study were a subset of the larger cohort of schoolchildren in Mexico City previously evaluated $[11,12]$. The present report includes data obtained from 55 asthmatic and 40 non-asthmatic schoolchildren who were enrolled during the first 10 months of the study and followed for an average of 22 weeks (fig. 1). These children attended 37 of the total of 107 schools represented in the larger study. Lung function was measured and respiratory health assessed every 15 days during the follow-up period.

\section{Location and population}

The overall study population consisted of schoolchildren living in three Mexico City municipalities: Iztapalapa, Iztacalco and Netzahualcoyotl. These regions are characterised by high levels of traffic-related emissions. The 55 asthmatic children included in the present analysis were recruited from clinics at the Hospital Infantil de Mexico Federico Gomez, one of the largest paediatric hospitals in the city. The diagnosis and severity of their asthma was based on clinical criteria and response to treatment; severity was rated by a paediatric allergist as mild (intermittent or persistent), moderate or severe, according to the Global Initiative for Asthma (GINA) guidelines [13]. 40 non-asthmatic children were recruited by asking the asthmatic children to invite a schoolmate or a friend from their neighbourhood. The children in both groups were 6-14 yrs old. They lived in the study area, attended public schools located close to their home, were volunteers and were not selected using probability-based sampling. All procedures were explained to the parents, who signed an informed consent form. The children also gave their informed assent. The study protocol was reviewed and approved by ethics committees at both the National Institute of Public Health and the Hospital Infantil de Mexico.

\section{Data collection procedures}

A general purpose questionnaire (adapted from existing survey instruments) was used to collect data on sociodemographic variables, past health history and potential indoor environmental exposures (tobacco smoke and pets in the home). Allergy test results, medication used and medical visits over the past 2 yrs were obtained from medical records. A respiratory symptom questionnaire was applied and lung function was measured at baseline and every 15 days during follow-up.

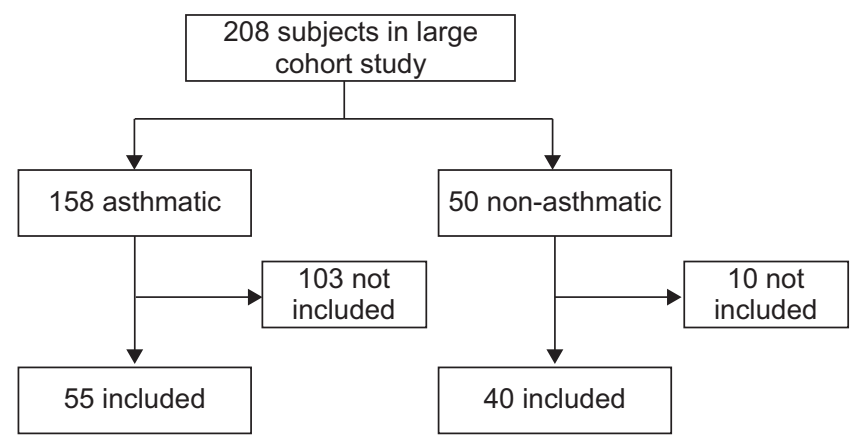

FIGURE 1. Flow chart of study design.

\section{Spirometry}

A total of 186 measurements of lung function were performed among asthmatic children and 122 among non-asthmatic schoolchildren. Measurements were repeated an average of three times (range 1-9) per subject during the study period using an Easy One spirometer (ndd Medical Technologies, Andover, MA, USA), according to American Thoracic Society (ATS) standards. Spirometric methods and the validation process have been detailed in our previous reports [11].

\section{Exposure assessment}

Local monitoring of PM2.5 was undertaken for continuous periods of 15 days ( 2 weeks) at different times in the 37 public schools attended by the sub-group of children $(n=95)$ participating in the present study (fig. 1). PM2.5 concentration was measured at each school 14 times (range 1-26), on average, during the period June 2003 to June 2005. In addition, measurements were conducted of EC fractions of PM2.5 in 207 Teflon filters from a subsample of 20 schools. EC concentrations were measured at each school three times (range 1-9), on average, during this period. The schools were chosen for monitoring based on their distance $(24-800 \mathrm{~m})$ to the closest roadways with high traffic density and all schools were close to the children's homes. Five of the schools were in IztapalapaWest, six were in Iztapalapa-East, four were in Iztacalco and five were in Nezahualcoyotl. Each child's home and school was geo-referenced using a geographic information system. Exposure was estimated from the 24-h average local outdoor EC fractions of PM2.5 concentration at the child's school and the closest monitoring school was assigned to the child. Meteorological (temperature and humidity) and PM2.5 concentration data were also obtained from the Mexico City government from four fixed-site central monitoring (RAMA; Red Automática de Monitoreo Atmosférico) locations within the study area for the study period.

Mini-Vol portable air samplers (version 4.2; Airmetrics, Eugene, OR, USA) with flows of $5 \mathrm{~L} \cdot \mathrm{min}^{-1}$ using 47-mm Teflon membrane filters (R2PJ047; Pall Gelman, Ann Arbor, MI, USA) were used to monitor local daily 24-h outdoor PM2.5 concentrations. Mini-Vols were located on school rooftops (height $3 \mathrm{~m}$ above the ground); care was taken not to place monitors within $90 \mathrm{~cm}$ of walls and windows or close to plants or trees. Gravimetric analysis of the 47-mm Teflon filters was performed at the air laboratory of the National Center for Environmental Research and Training (CENICA) in Mexico City. EC concentrations for visible light absorption $\left(b_{a b s}\right)$ (as a marker for diesel "soot") was measured using transmission densitometry (Tobias Associates Inc., Ivyland, PA, USA) at the Desert Research Institute, Las Vegas, NV, USA, according to the procedures previously described by WATSON et al. [14]. The transmission densitometry method measures optical density with an incandescent broadband lamp (400-650 nm, peaking at $575 \mathrm{~nm}$ ) transmitted through a glass diffuser. Transmittance is measured before and after Teflon filter exposure to determine particle $b_{a b s}$ and the difference in the logarithms of the transmitted light is proportional to the absorption of the particle deposit [15]. PM2.5 $b_{\text {abs }}$ has been found to be highly correlated with collocate EC analysis by the thermal/optical reflectance method [16] and provides reliable information on the variability of EC levels related to traffic exhaust; these results can be used as a marker for diesel exhaust particles [17]. 
TABLE 1 Demographic characteristics and main outcomes of the study population

\begin{tabular}{|c|c|c|c|c|c|c|c|c|}
\hline \multirow[t]{2}{*}{ Variable } & \multicolumn{3}{|c|}{ Participants } & \multicolumn{3}{|c|}{ Non-participants } & \multicolumn{2}{|c|}{ p-value } \\
\hline & A & Non-A & p-value & A & Non-A & p-value & A versus $A$ & $\begin{array}{c}\text { Non-A versus } \\
\text { non-A }\end{array}$ \\
\hline Subjects $\mathbf{n}$ & 55 & 40 & & 103 & 10 & & & \\
\hline Males & 73.4 & 26.5 & 0.002 & 60.0 & 60.0 & 0.605 & 0.608 & 0.121 \\
\hline Height $\mathbf{c m}$ & $137.2 \pm 12.2$ & $133.5 \pm 11.9$ & 0.151 & $135.8 \pm 15.0$ & $143.0 \pm 15.6$ & 0.104 & 0.564 & 0.042 \\
\hline Maternal schooling yrs & $8.8 \pm 3.1$ & $8.8 \pm 3.0$ & 0.9231 & $10.3 \pm 2.8$ & $10.6 \pm 2.7$ & 0.799 & 0.004 & 0.062 \\
\hline Paternal smoking at home & 54.6 & 38.2 & 0.353 & 54.88 & 83.33 & 0.600 & 0.285 & 0.091 \\
\hline Maternal smoking at home & 36.8 & 21.9 & 0.105 & 43.48 & 50 & 0.361 & 0.013 & 0.033 \\
\hline Pets at home & 54.6 & 65 & 0.306 & 57.69 & 93.33 & 0.009 & 0.738 & 0.045 \\
\hline Carpet at home & 7.6 & 30 & 0.006 & 18 & 46.67 & 0.020 & 0.094 & 0.341 \\
\hline Mild persistent asthma & 23.6 & & & 28.85 & & & & \\
\hline Mild intermittent asthma & 56.4 & & & 54.81 & & & & \\
\hline $\mathrm{FEV}_{1} \mathrm{~L} \cdot \mathrm{s}^{-1}$ & $1.9 \pm 0.6$ & $1.9 \pm 0.6$ & 0.76 & $1.9 \pm 0.7$ & $2.2 \pm 0.6$ & 0.760 & 0.437 & 0.146 \\
\hline FVC L. $\mathrm{s}^{-1}$ & $2.3 \pm 0.7$ & $2.1 \pm 0.6$ & 0.173 & $2.9 \pm 0.8$ & $2.6 \pm 0.7$ & 0.144 & 0.419 & 0.141 \\
\hline FEF $25-75 \%$ L & $2.0 \pm 0.7$ & $2.3 \pm 0.9$ & 0.051 & $2.0 \pm 1.0$ & $2.5 \pm 0.9$ & 0.087 & 0.937 & 0.571 \\
\hline
\end{tabular}

Data are presented as $\%$ or mean \pm SD, unless otherwise stated. A: asthmatic; non-A: non-asthmatic; FEV1: forced expiratory volume in $1 \mathrm{~s}$; FVC: forced vital capacity; FEF25-75\%: forced expiratory flow at 25-75\% of FVC.

\section{Statistical analysis}

The basic characteristics of the two groups of children were compared by bivariate analysis using the unpaired t-test, Fisher's exact test or the Chi-squared test, depending on variable type.

In order to analyse the variation in lung function due to shortterm exposure to local outdoor EC fractions of PM2.5 concentration, we used linear mixed effects models with random intercept (xtreg command in Stata software (Stata Corp., college Station, TX, USA)), with a continuous response for longitudinal data. The models were run to evaluate exposure effects on the same day. That is, the association was calculated by selecting the day that pulmonary function was performed and assigning the measurement of local EC for the same day, considering average EC concentrations during $24 \mathrm{~h}$. This enabled us to appreciate the variability within and between subjects. We ran models with both random intercept and random slope, and with random intercept only. As the coefficients were similar in both types of models, we present the results from the linear mixed model with random intercept only, as previously reported [11].

Models were adjusted for potential confounding factors, including sex, body mass index (BMI), previous day minimum temperature, outside physical activity and chronological time; data were stratified by characteristics of the subjects studied. Other variables were not significant $(\mathrm{p}>0.10)$ and did not alter the results by $>1 \%$, such as age, socioeconomic index (considering the mother's education and the child's school type), outdoor activities, exposure to environmental tobacco smoke, use of antiallergic medicine and season. Pearson correlations were determined between PM2.5 concentrations at the fixed site monitoring stations and local monitoring of PM2.5, and with local outdoor EC fractions of PM2.5 concentration. Analyses were conducted using Stata software version 9.2.

\section{RESULTS}

Only 95 of the 208 schoolchildren participating in the larger cohort study were included in the present report. The characteristics of the study population and main outcomes (participants versus non-participants) are presented in table 1; we did not observe significant differences between groups with respect to the main variables. The mean $\pm \mathrm{SD}$ age of participants was $9.7 \pm 1.9 \mathrm{yrs}$ for the asthmatic and $9.3 \pm 2.0 \mathrm{yrs}$ for the non-asthmatic children. $56 \%$ of the asthmatic children were classified as having mild intermittent, $23.6 \%$ as having mild persistent and $20.0 \%$ as having moderate persistent asthma. $81 \%$ of the asthmatic children and $70 \%$ of the non-asthmatic children had positive skin prick tests. The most common sensitivities were to house dust mite (Dermatophagoides pteronyssinus), cat (Fel D1) and cockroach (American blatella) allergens. A total of 186 measurements of lung function were made among the asthmatic children and 122 among the non-asthmatic children. Measurements were repeated an average of three times (range 1-9) per subject during the study period. Lung function was similar for both groups (table 1).

\section{Environmental exposure data}

The 24-h mean \pm SD of PM2.5 at the schools was $25.5 \pm 13.7 \mu \mathrm{g} \cdot \mathrm{m}^{-3}$ (range $3.1-96.1 \mu \mathrm{g} \cdot \mathrm{m}^{-3}$ ) during the study period. The 24-h average of EC was $92.7 \pm 54.7 \mathrm{Mm}^{-1}$ (range of $11.1-210.5 \mathrm{Mm}^{-1}$ ) (table 2). Local measurements of PM2.5 conducted at the 


\begin{tabular}{|c|c|c|c|c|}
\hline \multirow{2}{*}{$\begin{array}{l}\text { TABLE } 2 \\
\text { Variables }\end{array}$} & \multicolumn{4}{|c|}{$\begin{array}{l}\text { Air pollutants and climatic variables during the } \\
\text { study period }\end{array}$} \\
\hline & & Mean $\pm S D$ & $\begin{array}{c}\text { Interquartile } \\
\text { range }^{\#}\end{array}$ & Min-max \\
\hline \multicolumn{2}{|c|}{$\mathrm{EC} \mathrm{Mm}^{-1} 24-\mathrm{h}$ average } & $92.7 \pm 54.7$ & 100.93 & $11.1-210.5$ \\
\hline \multicolumn{2}{|c|}{$\begin{array}{l}\text { Local PM2.5 } \mu \mathrm{g} \cdot \mathrm{m}^{-3} 24-\mathrm{h} \\
\text { average }\end{array}$} & $25.5 \pm 13.0$ & 13.7 & $3.1-96.1$ \\
\hline \multicolumn{2}{|c|}{ Temperature $1-\mathrm{h}$ minimum ${ }^{\circ} \mathrm{C}$} & $11.4 \pm 3.0$ & 4.0 & $0.7-17.9$ \\
\hline \multicolumn{2}{|c|}{ Humidity $1-\mathrm{h}$ minimum } & $34.8 \pm 11.6$ & 18.1 & $5.9-70.5$ \\
\hline
\end{tabular}

children's schools were correlated with levels at the central monitoring stations $(\mathrm{r}=0.77)$; the correlation between $\mathrm{EC}$ and local measurements of PM2.5 in the school was 0.47 .

\section{Association between lung function and EC exposure}

The associations between traffic-related carbon exposure and lung function are shown in table 3. After adjusting for sex, BMI, previous day minimum temperature, outdoor physical activity and chronological time, an average increase of $100.93 \mathrm{Mm}^{-1}$ in EC levels (equivalent to one interquartile range (IQR)) was associated with an important negative effect on FEV1 (-62.0 (95\% CI -123.3- -1.2) $\mathrm{mL})$, on forced vital capacity (FVC) $(-48.0(95 \%$ CI -124.4-26.6) $\mathrm{mL}$ ) and on forced expiratory flow at $25-75 \%$ of FVC (FEF25-75\%) (-111 (95\% CI -228.3- -4.1) mL) among asthmatic children, equal to $3.3,2.1$ and $5.5 \%$, respectively. In nonasthmatic children, we also observed an important negative effect on FEV1 (-95.0 (95\% CI -182.3- -8.5) mL), on FVC (-105.0 (95\% CI $-197.0-13.7) \mathrm{mL})$ and on FEF25-75\% (-142.0 (95\% CI $-347.9-63.8) \mathrm{mL}$ ), equal to $5.0,5.0$ and $6.2 \%$, respectively. When the analysis was stratified by atopy, the association was only significant for atopic children. In the model for atopic children, the magnitude of the association was -64.1 (95\% CI -123.4- -4.6) $\mathrm{mL}$ for FEV1 and -138.6 (95\% CI -241.5- -35.6) mL for $\mathrm{FEF} 25-75 \%$, equal to 3.3 and $6.0 \%$, respectively, for an IQR increase in EC concentration (table 3).

\section{DISCUSSION}

The results of the present study show that lung function in Mexican schoolchildren was inversely associated with exposure to EC, with the main effect related to EC exposure on the day lung function was measured. This is one of the first prospective studies to report an association between exposure to EC, assessed in the child's immediate environment, and lung function decrements in schoolchildren with and without asthma. This effect was more significant in atopic children, regardless of their asthma status.

In the present study, while we observed a decrease in all lung function variables analysed in both asthmatic and non-asthmatic children, the most robust findings were between increased EC and a reduction in FEV1 and FEF25-75\%. These inverse associations are consistent with those reported in other studies relating traffic exposures to lung function, and suggest a short-term effect of this pollutant. Long-term effects on lung function have also been observed. GAUDERMAN et al. [1] measured ambient air quality in 12 communities in southern California, USA, and compared lung function in children living in the most polluted communities with those in the less polluted areas. They reported an inverse association between FEV1 $(\mathrm{mL})$ and EC (-87.9 (95\% CI $-146.4-29.4) \mathrm{mL}, \mathrm{p}=0.007)$ for an increase of $1.2 \mu \mathrm{g} \cdot \mathrm{m}^{-3}$ in $\mathrm{EC}$, corresponding to a decrease in FEV1 of $\sim 4.4 \%$. KULKARNI et al. [6] assessed the carbon content of alveolar macrophages obtained by inducing sputum production with hypertonic saline in healthy schoolchildren in Leicester, UK, and reported inverse associations between carbon content and lung function expressed as $\%$ of predicted values. For each increase of $1 \mu \mathrm{m}^{2}$ in carbon content they found a $12.9 \%$ decrease in FVC, a $17 \%$ decrease in FEV1 and a 34.7\% decrease in FEF25-75\%. Similar results have been reported for adults [4]. In a prospective study including 272 females, FRANCO et al. [18] reported a $1.1 \%$ decrease (95\% CI $-2.5-0.3 \%$ ) in FEV1, a $0.6 \%$ decrease $(95 \%$ CI $-1.9-0.6 \%$ ) in FVC and a $3.0 \%$ decrease (95\% CI $-5.8--0.2 \%)$ in FEF25-75\% for an interquartile range increase $\left(22 \mu \mathrm{g} \cdot \mathrm{m}^{-3}\right)$ in black carbon exposure.

The association we report here between EC and lower lung function was seen in both asthmatic and non-asthmatic children. And though asthmatic children are generally considered to be at increased risk of the adverse consequences of environmental exposures, our study design does not allow for a true assessment of this premise. We recruited asthmatic children from the clinics of the Hospital Infantil de Mexico Federico Gomez. These children then invited a friend who attended the same school or lived in the same neighbourhood to participate

\begin{tabular}{|c|c|c|c|}
\hline TABLE 3 & \multicolumn{3}{|c|}{$\begin{array}{l}\text { Association between } 24 \mathrm{~h} \text { average elemental carbon (EC) (coefficients per increase in interquartile range) and lung } \\
\text { function parameters in schoolchildren living in Mexico City, 2003-2005 }\end{array}$} \\
\hline EC models & $\mathrm{FEV} 1 \mathrm{~mL} \cdot \mathrm{s}^{-1}$ & $\mathrm{FVC} \mathrm{mL} \cdot \mathrm{s}^{-1}$ & FEF25-75\% ${ }^{\#} \mathrm{~mL}$ \\
\hline Asthmatic ${ }^{\pi}$ & $-62.0(-123.3--1.2)^{\star}$ & $-48.0(-124.4-26.6)$ & $-111.0(-228.3--4.1)^{*}$ \\
\hline Non-asthmatic ${ }^{\#}$ & $-95.0(-182.3--8.5)^{*}$ & $-105.0(-197.0--13.7)^{\star}$ & $-142.0(-347.9-63.8)$ \\
\hline Atopic $^{+}$ & $-64.1(-123.4--4.6)^{\star}$ & $-46.0(-120.3-28.1)$ & $-138.6(-241.5--35.6)^{\star}$ \\
\hline
\end{tabular}


as controls. While these groups had similar demographic characteristics (table 1), there were more females in the control group and they had higher FEF25-75\%. A larger study recruiting a community-based sample of asthmatic and non-asthmatic children will be required to determine whether asthmatic children are indeed more susceptible to exposure to trafficrelated pollution.

An important finding from the present study was that the inverse association between EC and lung function was mostly seen in atopic children, regardless of their asthma status. Exposure to diesel exhaust particles is associated with an increased risk of allergic sensitisation [7]. Thus, it is possible that chronic exposure to higher levels of EC, as an index of exposure to traffic-related pollution in general and to diesel exhaust particles in particular, increased the risk of allergic sensitisation in these children and had a short-term effect on lung function as a result of acute exposure. While our study is not ideal for assessing this possibility, the rate of allergic sensitisation in the non-asthmatic group $(70.0 \%)$ was higher than expected. In addition, in a prior analysis we observed a stronger effect of PM2.5, measured at fixed central monitoring stations, and lung function decrement among a larger group of atopic children [11], lending more support to our current results. Again, specific studies will need to be conducted to examine the interrelationships between exposure to traffic-related pollution, allergic sensitisation and lung function in children.

Exposure assessment among children is difficult and individual exposure is not well represented by data obtained from fixed central monitoring stations. Thus, an important strength of the present study is that we were able to measure EC in filters collected locally within the schools attended by the children, thereby providing a better exposure assessment than using central monitoring sites [19-21]. In addition, few studies have used real-time local measurements that enable the effects of EC to be assessed, as presented in this study.

Some limitations must be taken into account when interpreting the results of this study. The temporal variations in each child's exposure were assumed to follow the same tendencies on days with and without EC measurements. To strengthen the validity of this assumption, for the entire period of the study we observed high correlations $(r=0.77)$ between measurements of PM2.5 from fixed central monitoring sites and those from local monitoring conducted at the schools. The correlation between EC and local PM2.5 particles was also highly significant $(p<0.001)$.

In summary, the data from the present study show adverse effects of EC exposure on lung function among atopic schoolchildren, regardless of their asthma status. These data show the detrimental effects of locating schools in areas exposed to heavy traffic.

\section{SUPPORT STATEMENT}

The study was supported by Mexican Sciences and Technology Council (CONACYT) Grant no. 38911-M and 2002-C01-7624.

\section{STATEMENT OF INTEREST}

None declared.

\section{REFERENCES}

1 Gauderman WJ, Avol E, Gilliland F, et al. The effect of air pollution on lung development from 10 to 18 years of age. N Engl J Med 2004; 351: 1057-1067.

2 Gehring U, Cyrys J, Sedlmeir G, et al. Traffic-related air pollution and respiratory health during the first 2 yrs of life. Eur Respir $J$ 2002; 19: 690-698.

3 Hong CY, Chia SE, Widjaja D, et al. Prevalence of respiratory symptoms in children and air quality by village in rural indonesia. J Occup Environ Med 2004; 46: 1174-1179.

4 Rodriguez C, Tonkin R, Heyworth J, et al. The relationship between outdoor air quality and respiratory symptoms in young children. Int J Environ Health Res 2007; 17: 351-360.

5 Wichmann FA, Müller A, Busi LE, et al. Increased asthma and respiratory symptoms in children exposed to petrochemical pollution. Allergy Clin Immunol 2009; 123: 632-638.

6 Kulkarni K, Pierse N, Rushton L, et al. Carbon in airway macrophages and lung function in children. New Engl J Med 2006; 355: 21-30.

7 Casillas AM, Nel AE. An update on the immunopathogenesis of asthma as an inflammatory disease enhanced by environmental pollutants. Allergy Asthma Proc 1997; 18: 227-233.

8 Takafuji S, Nakagawa T. Air pollution and allergy. I Investig Allergol Clin Immunol 2000; 10: 5-10.

9 Escamilla-Nuñez MC, Barraza-Villarreal A, Hernandez-Cadena L, et al. Traffic-related air pollution and respiratory symptoms among asthmatic children, resident in Mexico City: the EVA cohort study. Respir Res 2008; 9: 74.

10 Li N, Wang M, Bramble LA, et al. The adjuvant effect of ambient particulate matter is closely reflected by the particulate oxidant potential. Environ Health Perspect 2009; 117: 1116-1123.

11 Barraza-Villarreal A, Sunyer J, Hernandez-Cadena L, et al. Air pollution, airway inflammation, and lung function in a cohort study of Mexico City schoolchildren. Environ Health Perspect 2008; 116: 832-838.

12 Romieu I, Barraza-Villarreal A, Escamilla-Nuñez C, et al. Exhaled breath malondialdehyde as a marker of effect of exposure to air pollution in children with asthma. J Allergy Clin Immunol 2008; 121: 903-909.

13 Global Initiative for Asthma. Global Initiative for Asthma (GINA). Global Stratey for Asthma Management and Prevention. 2006. www.ginasthma.org/guidelines-archived-2006-revision.html.

14 Watson JG, Chow JC, Chen LW. A summary of organic and elemental carbon/black carbon analysis methods and intercomparisons. J Aerosol Air Qual Res 2005; 5: 65-102.

15 Chow JC, Lowenthal DH, Watson JG, et al. Light absorption by black sand dust. Appl Opt 2000; 39: 4232-4236.

16 Chow JC, Watson JG, Chen LW, et al. The IMPROVE_A temperature protocol for thermal/optical carbon analysis: maintaining consistency with a long-term database. J Air Waste Manag Assoc 2007; 57: 1014-1023.

17 Wolff GT. Characteristics and consequences of soot in the atmosphere. Environ Int 1985; 11: 259-269.

18 Franco S, Gryparis A, Schwartz J, et al. Association between trafficrelated black carbon exposure and lung function among urban women. Environ Health Perspect 2008; 116: 1333-1337.

19 Wheeler AJ, Smith-Doiron M, Xu X, et al. Intra-urban variability of air pollution in Windsor, Ontario - measurement and modeling for human exposure assessment. Environ Res 2008; 106: 7-16.

20 Zhang JJ, Lioy PJ. Human exposure assessment in air pollution systems. Scientific World Journal 2002; 23: 497-513.

21 Zou B, Wilson JG, Zhan FB, et al. Air pollution exposure assessment methods utilized in epidemiological studies. J Environ Monit 2009; 11: $475-490$. 